\title{
The positive prognostic effect of stromal CD8+ tumor-infiltrating $T$ cells is restrained by the expression of HLA-E in non-small cell lung carcinoma
}

\author{
Mehrdad Talebian Yazdi ${ }^{1}$, Sander van Riet $^{1}$, Annemarie van Schadewijk ${ }^{1}$, Marta \\ Fiocco $^{3,4}$, Thorbald van Hall ${ }^{2}$, Christian Taube ${ }^{1}$, Pieter S. Hiemstra ${ }^{1}$, Sjoerd H. van \\ der burg ${ }^{2}$ \\ ${ }^{1}$ Department of Pulmonology, Leiden University Medical Center, Leiden, The Netherlands \\ ${ }^{2}$ Department of Clinical Oncology, Leiden University Medical Center, Leiden, The Netherlands \\ ${ }^{3}$ Department of Medical Statistics and Bioinformatics, Leiden University Medical Center, Leiden, The Netherlands \\ ${ }^{4}$ Institute of Mathematics, Leiden University, Leiden, The Netherlands \\ Correspondence to: Sjoerd H. van der burg, e-mail: shvdburg@lumc.nl \\ Keywords: CD8+ T cells, HLA class I, HLA-E, non-small cell lung cancer, survival \\ Received: August 23, $2015 \quad$ Accepted: November 21,2015 Published: December 02, 2015
}

\section{ABSTRACT}

INTRODUCTION: Tumor-infiltrating CD8 + $\mathrm{T}$ cells are associated with improved clinical outcomes in non-small cell lung cancer (NSCLC). Here we studied their prognostic effect in the context of the expression of HLA molecules that are key in tumor recognition (HLA-A, B and C) or suppression of immunity (HLA-E) as this is still unknown.

METHODS: Tumor tissue of 197 patients with resected pulmonary adenocarcinoma was analyzed for the presence of CD8 $+T$ cells and the expression of $\beta 2$-microglobulin, HLA-A, HLA-B/C and HLA-E. The relation of these parameters with overall survival (OS) was assessed.

RESULTS: Loss and low expression of HLA-A or HLA-B/C was found in $44 \%$ and $75 \%$ of cases respectively. A high CD8+ tumor infiltration was strongly associated with clinical benefit only when the tumors retained good expression of HLA-A and HLA-B/C $(p=0.004)$. In addition, more than $70 \%$ of the tumors were found to display a high expression of HLA-E. The expression of HLA-E by tumor cells was an independent negative prognostic factor for OS $(p=0.031)$. Importantly, a dense stromal CD8+ T cell infiltration was strongly associated with improved OS only in HLA-E negative tumors $(p=0.005)$ and its prognostic effect was completely abolished when tumors highly expressed HLA-E $(p=0.989)$.

CONCLUSIONS: CD8+ T cell infiltration strongly contributes to a better prognosis in NSCLC when the tumor cells retain the expression of classical HLA class I and do not express HLA-E. Therefore, analysis of HLA-A, -B/C and HLA-E expression should be included as biomarkers to predict the response to immunotherapy.

\section{INTRODUCTION}

Non-small cell lung cancer (NSCLC) is a leading cause of death globally [1-3]. The reported overall 5 -year survival is $17 \%[2,4]$, indicating the need for therapies that extend survival and provide a better quality of life. T-cell based immunotherapies hold great promise as a powerful new approach to treat NSCLC as treatment with antibodies interrupting immune checkpoint PD-1/PD-L1 has shown great clinical benefit in NSCLC [5-7]. The programmed death 1 (PD-1) receptor blocking antibody nivolumab was recently approved by the U.S. Food and Drug Administration to treat metastasized squamous NSCLC [8].

T-cell based immunotherapy of cancer is highly dependent on the presentation of tumor-specific antigens in the context of human leukocyte antigen (HLA) class I or class II molecules to tumor-infiltrating T cells (TILs) [9]. In NSCLC, the density of TILs, in particular the number of 
stromal CD8+ T cells, have strong prognostic value [1015]. The expression of the classical HLA class I molecules $\mathrm{A}, \mathrm{B}$ and $\mathrm{C}$ in NSCLC, however, frequently is down regulated $[16,17]$ and was found to affect overall survival (OS) [18]. Remarkably, studies on the interaction between CD8+ T cell infiltration and the expression of classical HLA class I are limited to one study showing that loss of HLA class I is associated with a sparser T-cell infiltrate [19].

The non-classical HLA class I molecules E, F and G can also be expressed by cancer cells. HLA-G expression was associated with limited lymphoid infiltration and poor prognosis in NSCLC [20], potentially via increased regulatory T-cell activity [21]. The expression of HLA-F, acting via the immune inhibitory receptors ILT-2 and ILT-4 [22], also had a negative impact on the prognosis of NSCLC patients [23]. HLA-E, which binds to the inhibitory CD94/NKG2A receptor expressed by activated NK cells and CD8 T cells, can directly suppress innate and adaptive immunity when expressed by cancer cells [24, 25]. We have studied the expression of HLA-E in different cancers $[26,27]$ and found that the beneficial prognostic effect of infiltrating CTLs in ovarian cancer was thwarted by high expression of HLA-E [27]. However, the expression and prognostic effect of HLA-E in NSCLC has not been studied.

To investigate the prognostic value of $\mathrm{CD} 8+$ tumor infiltrating $\mathrm{T}$ cells in the context of HLA-A, B and $\mathrm{C}$ as well as HLA-E and its association with OS, we retrospectively studied a group of 197 patients with NSCLC. We exclusively focused on pulmonary adenocarcinoma not only because this is the main histological subtype in NSCLC $[1,28]$ but also because HLA loss has been reported to be less frequent than in squamous cell carcinoma, the other major subtype of NSCLC [16-19, 29] and therefore is expected to benefit the most from active T-cell-mediated immunotherapy. Our study revealed that the expression of HLA-E by tumor cells was an independent prognostic factor for OS. High expression of HLA-E neutralized the positive prognostic value of high stromal CD8 $+\mathrm{T}$ cell infiltration in NSCLC.

\section{RESULTS}

\section{Stromal CD8 T-cell infiltration correlates best with overall survival}

A cohort of 197 patients with pulmonary adenocarcinoma was evaluated. The grade of differentiation by the tumor was classified as either poor $(50 \%)$, moderate $(33 \%)$ or well differentiated $(17 \%)$. In $31 \%$ of cases, patients had advanced disease (stage III/IV) despite being classified as stage I/II based on pre-operative diagnostic modalities (Table 1). Mean age was 66 years (range 37- 90 years) and the number of males $(n=99)$ and females $(n=98)$ was evenly distributed.
The extent of CD8+ T-cell infiltration was studied by enumeration of intraepithelial and stromal CD8+ $\mathrm{T}$ cells in tumor sections. Examples of representative immunohistochemical stainings of $\mathrm{CD} 8+\mathrm{T}$ cells are displayed in Figure 1. Overall intraepithelial CD8+ T-cell infiltration ranged from 7 to 1460 cells $/ \mathrm{mm}^{2}$ tumor (mean 194; median 150), stromal CD8+ T cells from 35 to 1332 cells $/ \mathrm{mm}^{2}$ tumor (mean 348 ; median 320 ) and total CD8+ T cells from 32 to 1008 cells/ $\mathrm{mm}^{2}$ tumor (mean 271; median 246). There were no differences in total CD8+ T-cell tumor infiltration between males and females (chi square test, $\mathrm{p}=0.267$ ). Patients were divided in two groups with low or high CD8+ T cell infiltration, based on the mean CD8+ T-cell count for all patients, and the association with OS was plotted. A relatively strong stromal CD8+ T-cell infiltration displayed the best association with a beneficial clinical outcome (log-rank test, $\mathrm{p}=0.068$; Figure $2 \mathrm{~A}-2 \mathrm{C}$ ). The negative effect of low stromal CD8+ T-cell infiltration was magnified when the patients were divided on the basis of tertiles, with patients in the lower tertile defined as having low CD8+ stromal $\mathrm{T}$ cell infiltration and the other patients as having high stromal CD8 + T cell infiltration ( $\mathrm{p}=0.046$, Supplementary Figure S1), similar to what was reported before [10-14].

\section{Interaction between classical HLA class I expression and CD8+ $\mathrm{T}$ cells}

Assessment of the expression of classical HLA class I molecules was performed using antibodies against $\beta 2-\mathrm{M}$, HLA-A and HLA-B/C (Figure 1). $\beta 2-\mathrm{M}$ was expressed in $76 \%$ of cases, but HLA-A and HLA-B/C were expressed in only $56 \%$ and $25 \%$ of the cases, respectively (Table 1 ).

Subsequently, the association between tumor stage, HLA class I molecules and CD8+ T cell infiltration was assessed (Supplementary Table S1). High expression of HLA-A strongly correlated with high expression of HLA-B/C $(p=0.0001)$. A clear correlation existed between the presence or absence of functional HLA class I expression and the total number of tumor-infiltrating CD8+ T cells. Tumors with downregulation of HLA-A $(\mathrm{p}=0.012)$ or HLA-B/C $(\mathrm{p}=0.018)$ displayed on average lower numbers of total tumor-infiltrating $\mathrm{T}$ cells (Supplementary Table S1 and Supplementary Figure S2).

When patients were grouped according to a low or high expression of HLA-A or HLA-B/C, Kaplan Meier curves did not reveal any direct impact of classical HLA class I expression on clinical outcome (Figure 2D and $2 \mathrm{E}$ ). However, an interaction analysis between classical HLA expression and total CD8 $+\mathrm{T}$ cell infiltration in tumor tissue revealed a clear beneficial effect of a dense $\mathrm{CD} 8+\mathrm{T}$ cell infiltration in HLA-B/C positive tumors (HR $0.212,95 \%$ CI 0.074-0.606, $\mathrm{p}=0.004$ ) or HLA-A and HLA-B/C-positive tumors (HR 0.215, 95\% CI 0.069$0.673, p=0.008$ ) with respect to OS (Table 2 and Figure $3)$. This was not the case when CD8+ T-cell infiltration 
Table 1: Overview of stage, differentiation and immunohistochemical expression patterns in pulmonary adenocarcinoma

\begin{tabular}{|c|c|c|}
\hline \multicolumn{3}{|c|}{ Surgical-pathological staging (number, \%) } \\
\hline I & 62 & $(31 \%)$ \\
\hline II & 74 & $(38 \%)$ \\
\hline III & 35 & $(18 \%)$ \\
\hline IV & 26 & $(13 \%)$ \\
\hline \multicolumn{3}{|c|}{ Differentiation (number, \%) } \\
\hline Poor & 98 & $(50 \%)$ \\
\hline Moderate & 66 & $(33 \%)$ \\
\hline Well & 33 & $(17 \%)$ \\
\hline \multicolumn{3}{|c|}{ $\beta 2-\mathrm{M}$ (number, \%) } \\
\hline Low & 47 & $(24 \%)$ \\
\hline High & 150 & $(76 \%)$ \\
\hline \multicolumn{3}{|c|}{ HLA-A (number, \%) } \\
\hline Low & 87 & $(44 \%)$ \\
\hline High & 110 & $(56 \%)$ \\
\hline \multicolumn{3}{|c|}{ HLA-B/C (number, \%) } \\
\hline Low & 148 & $(75 \%)$ \\
\hline High & 49 & $(25 \%)$ \\
\hline \multicolumn{3}{|c|}{ HLA-E (number, \%) } \\
\hline Low & 55 & $(28 \%)$ \\
\hline High & 142 & $(72 \%)$ \\
\hline \multicolumn{3}{|c|}{ Total CD8+ (number, \%) } \\
\hline Low & 96 & $(59 \%)$ \\
\hline High & 68 & $(41 \%)$ \\
\hline \multicolumn{3}{|c|}{$\mathrm{CD} 8+$ in tumor (number, \%) } \\
\hline Low & 104 & $(64 \%)$ \\
\hline High & 59 & $(36 \%)$ \\
\hline \multicolumn{3}{|c|}{ CD8+ in stroma (number, \%) } \\
\hline Low & 92 & $(56 \%)$ \\
\hline High & 71 & $(44 \%)$ \\
\hline
\end{tabular}

was analyzed in the context of HLA-A expression only. These results indicate that the presence of high numbers of CD8+ T cells is correlated with a favorable prognosis when classical HLA class I expression by the primary tumor is retained.

\section{HLA-E expression is a strong negative determinant for OS}

In more than $70 \%$ of pulmonary adenocarcinoma cases a high expression of HLA-E was observed (Figure $1 \mathrm{~F}$ and Table 1 ). In $20.3 \%$ of these tumors displaying a functional HLA-E molecule, no expression of HLA-A and HLA-B/C was observed. The high expression of HLA-E was associated with worse OS (HR 0.632, 95\% CI 0.406-0.984, $\mathrm{p}=0.042$; Table 2 and Figure 2F). Since both stromal CD8+ T-cell infiltration and the expression of HLA-E displayed the strongest effects on overall survival as a single determinant (Figure $2 \mathrm{~B}$ and $2 \mathrm{~F}$, Supplementary Figure S1), a subsequent analysis was performed to study the interaction between these two factors. Clearly, a dense stromal CD8 + T cell infiltration showed a strong positive prognostic value in HLA-E negative tumors (HR 0.303, 95\% CI 0.124-0.741, 
$\mathrm{p}=0.009$; Figure 4A and 4B). However, this beneficial effect of a dense stromal CD8+ $\mathrm{T}$ cell infiltration disappears in patients with high expression of HLA-E (HR 1.004, 95\% CI 0.550-1.835, p=0.989; Figure 4C and 4D). In conclusion, the beneficial effect displayed by tumor-infiltrating stromal CD8 $+\mathrm{T}$ cells is impeded when HLA-E is highly expressed by tumors.

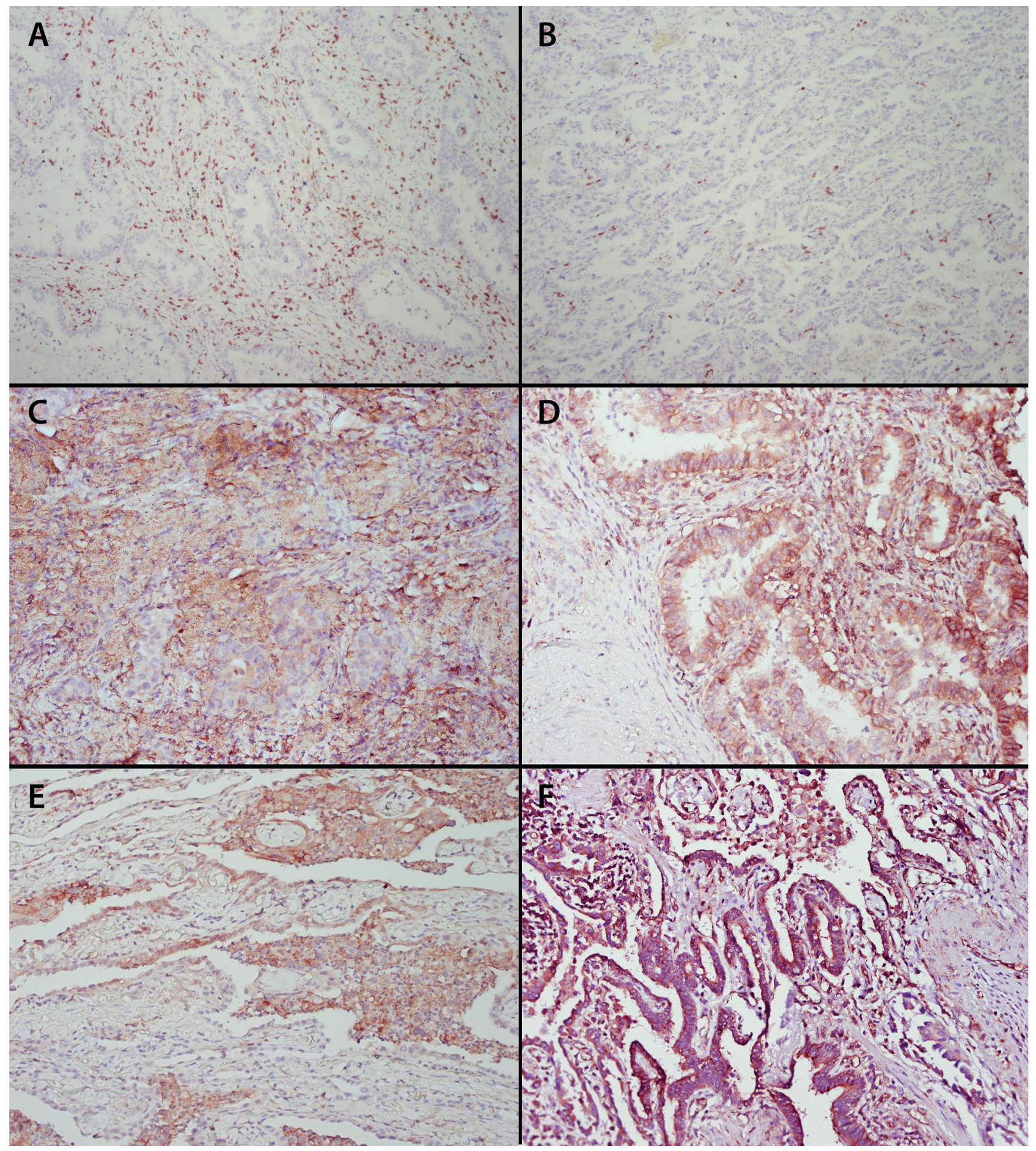

Figure 1: Staining of tumor infiltrating CD8+ T cells, $\beta 2$-microglobulin, HLA-A, HLA-B/C and HLA-E in pulmonary adenocarcinoma. Formalin-fixed, paraffin embedded tumor specimens of 197 non-small cell lung cancer patients were cut in $4 \mu \mathrm{m}$ sections and immunohistochemically stained for CD8, $\beta 2$-microglobulin, classical HLA-A and HLA-B/C, as well as non-classical HLA-E. According to the Ruiter scoring system [46] both the intensity and percentage of cells stained were assessed and expression was categorized as low (score 1-4) and high (score 5-9). Examples are shown of high A. and low B. stromal and intraepithelial CD8+ T cell infiltration; tumor with high $\beta 2$-microglobulin expression C. examples of HLA-A D. HLA-B/C E. and HLA-E F. staining. Original magnification x200. 


\section{HLA-E expression is an independent determinant of OS in pulmonary adenocarcinoma}

In order to assess the effect of each single variable on the relative risk of death, univariate and multivariate
Cox proportional hazards analysis were performed to quantify survival differences (Table 2). Tumor stage and male gender have been reported before as negative risk factors for OS in pulmonary adenocarcinoma [30] and indeed in our cohort high stage tumors (stage I/II vs stage III/IV, HR 0.619, 95\% CI 0.399-0.961, $\mathrm{p}=0.033$ ) as well
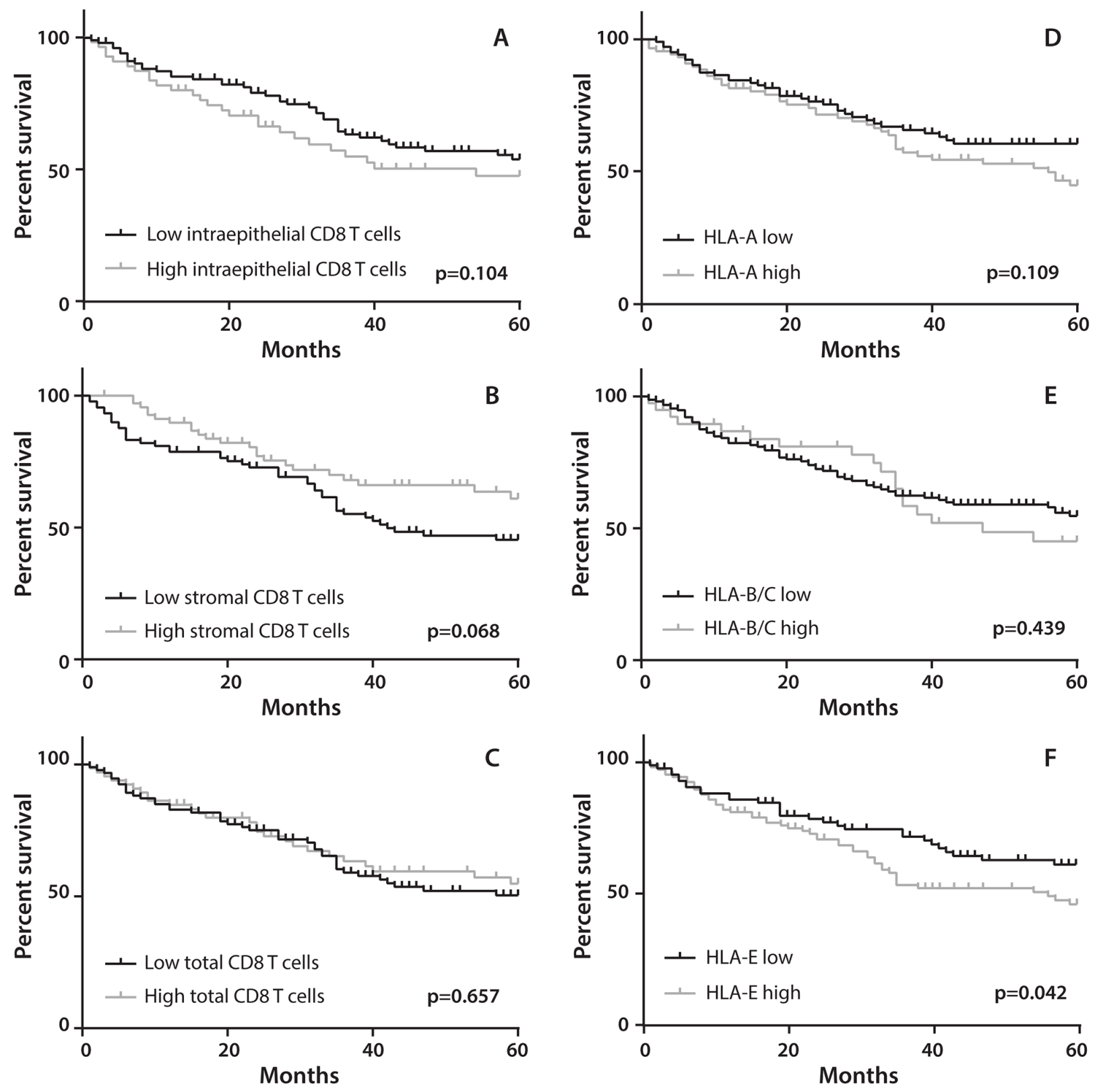

Figure 2: Association of CD8+ T cell infiltration and HLA expression with overall survival (OS). Patients were divided in two groups with low or high CD8+ T cell infiltration, based on the mean CD8+ T-cell count for all patients or on the basis of HLA expression. OS was defined as date of surgery until date of death due to any cause, or date of last follow-up with a maximum follow-up time of 5 years. Kaplan-Meier curves were used to estimate OS of the two groups whereas the log-rank test was used to compare the difference between the two curves. Survival curves are presented for A. patients with low $(\mathrm{n}=104)$ or high $(\mathrm{n}=59)$ intraepithelial CD8+ T cells (mean CD8+ cell count 194 cells/ mm2 tumor) ; B. low ( $\mathrm{n}=92)$ or high $(\mathrm{n}=71)$ stromal CD8+ T cells (mean CD8+ cell count 348 cells/ mm2 tumor) ; C. low ( $\mathrm{n}=95)$ or high $(\mathrm{n}=68)$ total $\mathrm{CD} 8+\mathrm{T}$ cells (mean $\mathrm{CD} 8+$ cell count 271 cells/ mm2 tumor). Furthermore, survival curves are presented for functional (i.e. positive staining for both HLA and $\beta 2-\mathrm{M})$ expression of D. HLA-A low ( $\mathrm{n}=106)$ and high $(\mathrm{n}=91) ;$ E. HLA-B/C low $(\mathrm{n}=156)$ and high $(\mathrm{n}=41) ;$ F. HLA-E low $(\mathrm{n}=87)$ and high $(\mathrm{n}=110)$. A significant correlation $(\mathrm{p}=0.042)$ was observed between low HLA-E expression and improved survival (F). 
Table 2: Univariate and multivariate cox proportional hazard analysis

\begin{tabular}{|c|c|c|c|c|c|c|}
\hline \multirow[t]{2}{*}{ Variable } & & \multicolumn{2}{|c|}{ Univariate analysis } & \multirow[b]{2}{*}{ p value } & \multirow{2}{*}{$\begin{array}{c}\text { Multivariate } \\
\text { analysis } \\
\text { HR (95\% CI) }\end{array}$} & \multirow[b]{2}{*}{ p value } \\
\hline & & HR & $(95 \% \mathrm{CI})$ & & & \\
\hline Stage & I/II vs III/IV & 0.619 & $(0.399-0.961)$ & 0.033 & $\begin{array}{l}0.587(0.377- \\
0.913)\end{array}$ & 0.018 \\
\hline Sex & Male vs Female & 1.834 & $(1.184-2.839)$ & 0.007 & $\begin{array}{l}1.785(1.152- \\
2.765)\end{array}$ & 0.009 \\
\hline Differentiation & poor vs medium/well & 1.423 & $(0.928-2.182)$ & 0.106 & & \\
\hline$\beta 2$-microglobulin & low vs high & 0.762 & $(0.442-1.314)$ & 0.328 & & \\
\hline HLA-A & low vs high & 0.703 & $(0.462-1.084)$ & 0.112 & & \\
\hline HLA-B/C & low vs high & 0.822 & $(0.498-1.358)$ & 0.443 & & \\
\hline HLA-E & low vs high & 0.632 & $(0.406-0.984)$ & 0.042 & $\begin{array}{c}0.612(0.392- \\
0.956)\end{array}$ & 0.031 \\
\hline Intraepithelial CD8 & low vs high & 0.682 & $(0.427-1.087)$ & 0.108 & & \\
\hline Stromal CD8 & low vs high & 1.560 & $(0.962-2.530)$ & 0.072 & $\begin{array}{c}1.613(0.993- \\
2.620)\end{array}$ & 0.054 \\
\hline Total CD8 & low vs high & 1.130 & $(0.705-1.812)$ & 0.659 & & \\
\hline HLA-E low & $\begin{array}{c}\text { high vs low stromal } \\
\text { CD8 }\end{array}$ & 0.303 & $(0.124-0.741)$ & 0.009 & & \\
\hline HLA-E high & $\begin{array}{c}\text { high vs low stromal } \\
\text { CD8 }\end{array}$ & 1.004 & $(0.550-1.835)$ & 0.989 & & \\
\hline Stromal CD8 high & high vs low HLA-E & 3.282 & $(1.308-8.232)$ & 0.011 & & \\
\hline Stromal CD8 low & high vs low HLA-E & 1.032 & $(0.585-1.818)$ & 0.914 & & \\
\hline HLA-B/C high & high vs low total CD8 & 0.212 & $(0.074-0.606)$ & 0.004 & & \\
\hline HLA-A and $\mathrm{B} / \mathrm{C}$ high & high vs low total CD8 & 0.215 & $(0.069-0.673)$ & 0.008 & & \\
\hline
\end{tabular}

Significant differences $(\mathrm{p}<0.05)$ are indicated in bold.

as male gender (HR 1.834, 95\% CI 1.184-2.839, $\mathrm{p}=0.007)$ were associated with worse OS. In the univariate analysis, a low expression of non-classical HLA-E by tumor cells was associated with a strong reduced risk of death in this cohort (HR 0.632, 95\% CI 0.406-0.984, $\mathrm{p}=0.042$ ). Presence of high stromal CD8+ T cells correlated with improved OS and reached near-significance (HR 1.560, $95 \%$ CI $0.962-2.530, \mathrm{p}=0.072$ ) and hence was included in the multivariate analysis together with tumor stage, gender and HLA-E expression.

Similar to the univariate analysis the positive effect of stromal CD8+ T cells on OS approached statistical significance (HR 1.613, 95\% CI 0.993-2.620, p=0.054) in the multivariate analysis. In addition to tumor stage and gender, the increased expression of HLA-E was significantly associated with OS (HR 0.612, 95\% CI 0.392-0.956, $\mathrm{p}=0.031$ ) indicating that low HLA-E expression is an independent positive prognostic factor for $\mathrm{OS}$ in pulmonary adenocarcinoma.

\section{DISCUSSION}

The infiltration of NSCLC by CD8 $+\mathrm{T}$ cells is positively associated with a longer OS irrespective of tumor stage [10-15] and our study confirms this association of $\mathrm{CD} 8+\mathrm{T}$-cell infiltration with better OS. It is important to identify the most important factors governing a successful attack of NSCLC by CD8+ T cells as illustrated by the facts that a) more than $40 \%$ of NSCLC patients respond to checkpoint inhibitor therapy [5-7]; and b) especially those patients are likely to respond in whom the tumor has generated neo antigens for CD8+ T cells [31]. One of the key molecules in this process is the expression of HLA molecules required to present tumor-specific peptides to T cells. When measured with a pan-HLA class I antibody, the loss of HLA is observed in almost half of the patients with pulmonary adenocarcinoma [16-19, 32]. We used antibodies to distinct the expression of HLA-A and HLA-B/C in order 

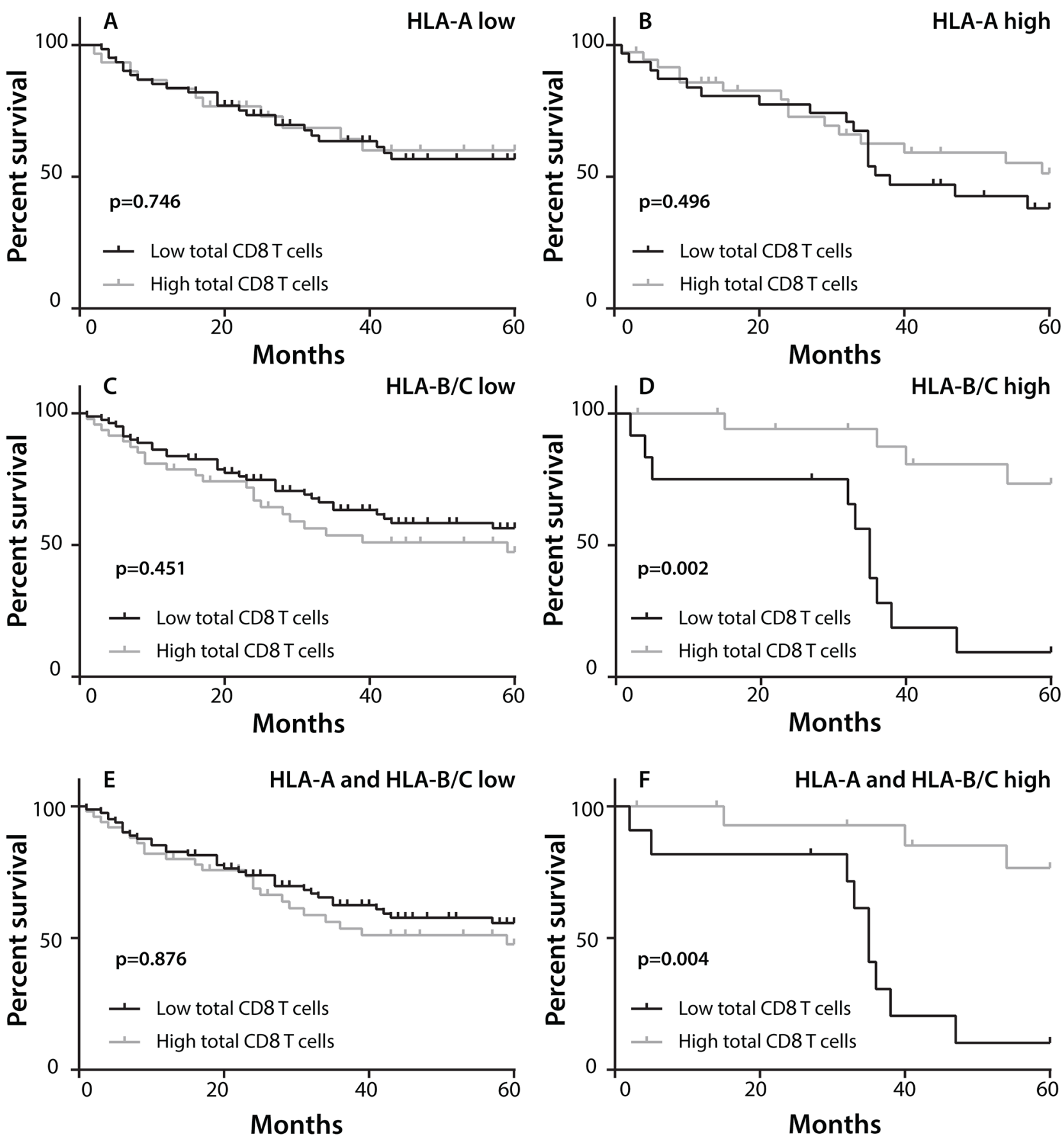

Figure 3. Effect of classical HLA class I expression and CD8+ T cell infiltration on overall survival (OS). Patients were divided in two groups with low or high CD8 $+\mathrm{T}$ cell infiltration, based on the mean CD8+ T-cell count for all patients and on the expression of classical HLA class I. Kaplan-Meier curves were constructed to estimate OS of the two groups whereas the log-rank test was used to compare the difference between the two curves. A, B. Comparison of OS between patients with low or high total $\mathrm{CD} 8+\mathrm{T}$ cell infiltration in the context of low ( $\mathrm{A} ; \mathrm{n}=63$ vs 30 , respectively) or high ( $\mathrm{B} ; \mathrm{n}=32$ vs 38 , respectively) HLA-A expression. C, D. Comparison of OS between patients with low $(n=83)$ or high $(n=47)$ CD8 + T cell infiltration of whom the tumors displayed low HLA-B/C expression (C). Comparison of OS between patients with HLA-B/C positive tumors and high $(n=21)$ or low $(n=12)$ total CD8+ T cell infiltration (D). E, F. Comparison of OS between patients with low $(n=62)$ or high $(\mathrm{n}=27) \mathrm{CD} 8+\mathrm{T}$ cell infiltration in tumors with low expression of both HLA-A and HLA-B/C (E). Comparison of OS between patients with low $(n=11)$ or high $(n=18)$ total $C D 8+T$ cell infiltration in the context of tumors with high expression of both HLA-A and HLA-B/C. (F) 
to chart the HLA loss in more detail (Table 1). We found that HLA-A was decreased in about $40 \%$ of the patients while the decrease in HLA-B/C expression was even as high as $75 \%$ which is in line with only one other study that reports specifically on loss of HLA-B/C in NSCLC [33]. In addition, interaction analyses of HLA expression and CD8+ T-cell infiltration led to the novel observation that the prognostic effect of a dense CD8+ T-cell tumor infiltration is only retained when tumors display a high expression of classical HLA class I, in particular HLA$\mathrm{B} / \mathrm{C}$ (Figure 3).

Other key molecules governing a successful attack of T cells in NSCLC are the so-called checkpoints [34]. The non-classical HLA-E molecule is the ligand for the inhibition receptor CD94/NKG2A and represents an important immunologic checkpoint $[24,25]$. This study is the first to show that a high expression of the non-classical HLA-E molecule affects overall survival in NSCLC. Both univariate and multivariate analysis revealed high HLA-E expression by tumor cells as an independent predictor of poor prognosis (Table 2 and Figure 2). The expression of HLA-E can inhibit the function of T lymphocytes and natural killer (NK) cells when it engages with CD94/ NKG2A [24, 25, 35], as well as activate these cells when HLA-E engages with CD94/NKG2C [36]. A few studies in breast cancer and cervical adenocarcinoma have reported survival benefit for HLA-E expressing tumors [37, 38] while others, similar to us, reported a negative effect of HLA-E on OS in ovarian cancer, colorectal cancer and gastric cancer [27, 39-41]. Potentially, the type of receptor for HLA-E expressed by CD8 T cells is at the basis of this difference. In ovarian cancer and colorectal cancer the $\mathrm{T}$ cells were shown to express the inhibitory receptor CD94/NKG2A [27, 39]. In line with previous studies in NSCLC, a dense stromal CD8+ T-cell tumorinfiltrate was associated with longer OS (Figure 2 and
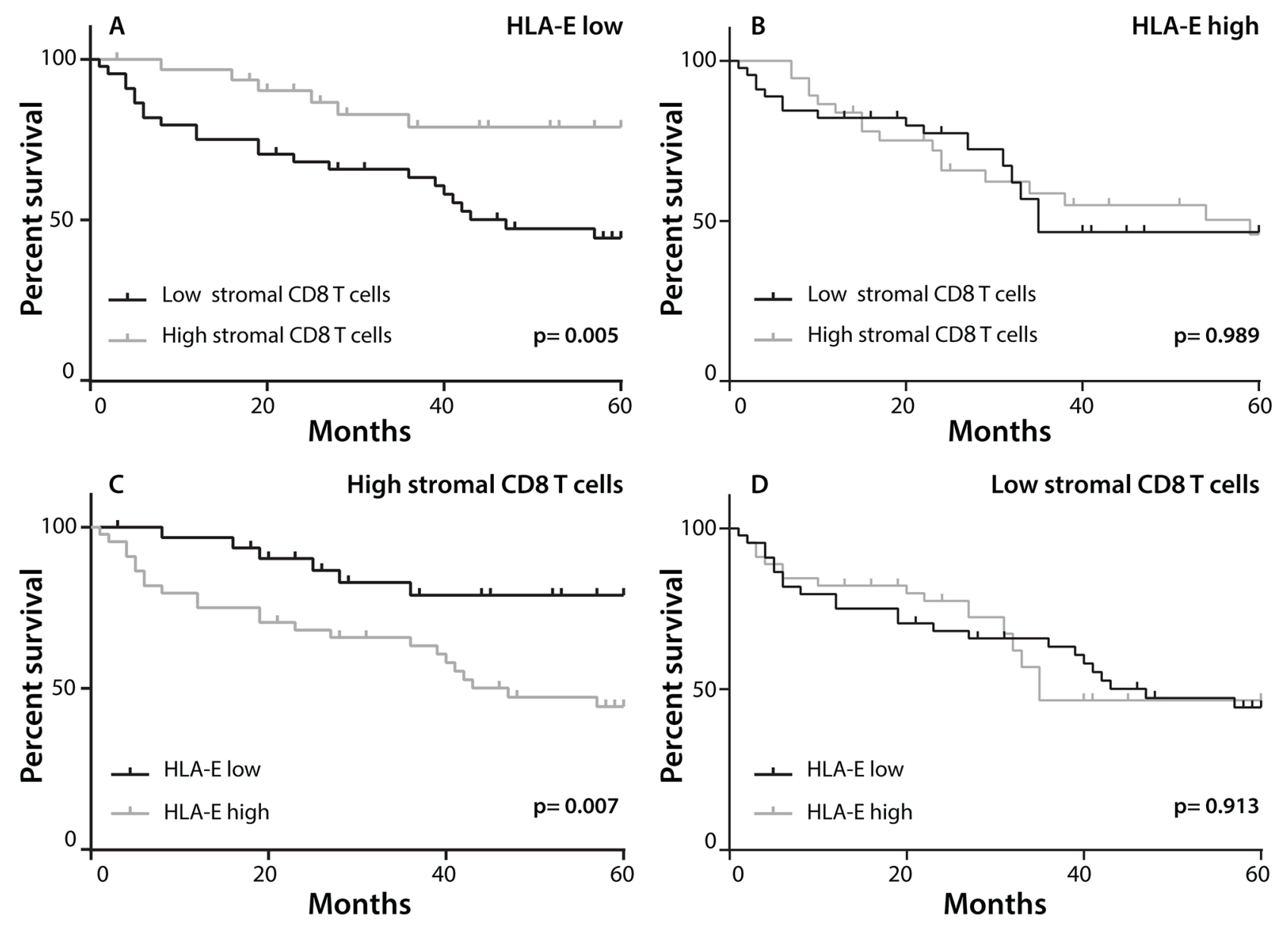

Figure 4: Prognostic benefit in HLA-E negative tumors with high CD8+ T cell infiltration. Patients were divided in two groups with low or high stromal CD8+ T cell infiltration, based on the mean CD8+ T-cell count for all patients and on the expression of HLA-E. Kaplan-Meier curves were constructed to estimate OS of the two groups whereas the log-rank test was used to compare the difference between the two curves. A. The effect of CD8+ T cell infiltration in patients with low HLA-E expression ( $\mathrm{n}=77$ ), showing that a high stromal CD8+ T cell infiltration was strongly associated with a better OS. B. The effect of a high stromal CD8+ T cell infiltrate was neutralized in tumors with high HLA-E expression $(n=86)$. C, D. Conversely, in patients with high stromal CD8+ T cell influx $(n=71)$, a high HLA-E expression is associated with a worse OS (C). In patients with low presence of stromal CD8+ T cells ( $\mathrm{n}=92$ ), HLA-E expression had no effect on OS (D). 
Supplementary Figure 1) [10-15]. In our study, a high expression of HLA-E by tumor cells clearly had a negative effect on CD8 $+\mathrm{T}$ cells. The positive prognostic effect of stromal CD8+ T cells on OS was only apparent in patients with low expression of HLA-E on their tumor cells. A high tumor expression of HLA-E completely abolished the prognostic effect of CD8+ T-cell infiltrate (Table 2 and Figure 4).

Our study on the interaction between tumor expressed HLA and CD8+ T-cell infiltration in relation to survival raises two important issues. Currently, CD8+ T-cell infiltration and expression of PD-L1 are being considered as biomarkers to select the population of NSCLC patients that are most likely to respond to checkpoint antibody therapy [42]. Based on our data showing that the prognostic effect of CD8+ T cells is most pronounced in those tumors still expressing HLA$\mathrm{B} / \mathrm{C}$, one could consider including the analysis of classical HLA class I expression in this selection procedure. The second issue concerns the improvement of current PD-1/ PD-L1 therapy or alternative checkpoint treatment strategies in NSCLC. Our results showed that about 70\% of the pulmonary adenocarcinomas displayed a high expression of HLA-E (Table 1). In view of its effect on both $T$ cells and NK cells, blocking HLA-E and/or its CD94-NKG2A inhibitory receptor may form a valuable target for the immunotherapy of NSCLC. Treatment with anti-NKG2A monoclonocal antibody was shown to overcome HLA-E mediated suppression of anti-tumor cellular cytotoxicity in vitro $[43,44]$ and this has resulted in a currently ongoing phase I/II trial in which patients with advanced head and neck cancer are treated with an anti-NKG2A monoclonocal antibody (ClinicalTrials.gov, Identifier: NCT02331875). Potentially, a combination of antibodies to these two different checkpoints may even have a synergistic effect.

In conclusion, our results confirm the pivotal protective role of tumor infiltrating CD8 $+\mathrm{T}$ cells in NSCLC and in addition show that their effect is particularly apparent when the tumor cells retain the expression of classical HLA class I and do not express the non-classical molecule HLA-E. These results warrant the inclusion of HLA-A, -B/C and HLA-E as biomarkers to predict the response to immunotherapy and the use of HLA-E or NKG2A blocking antibodies for the treatment of NSCLC.

\section{MATERIALS AND METHODS}

\section{Study population}

We retrospectively identified 197 patients diagnosed with non-small cell lung cancer (NSCLC), subtype adenocarcinoma, in the Leiden University Medical Center (LUMC) between 2000 and 2013. All patients underwent preoperative staging and were classified as stage I/II NSCLC and subsequently underwent surgical resection of the primary tumor with systematic lymph node dissection. After surgical removal of the tumor and its draining lymph nodes, patients were considered disease free. Tumor tissue, clinical data and follow-up data were collected from all patients. Staging of NSCLC was determined according to the TNM (Tumor, Node, Metastasis) classification using the updated guidelines of the International Association for the Study of Lung Cancer (IASLC) [45]. The use of archival tumor blocks was in accordance with guidelines from the Dutch Federation of Medical Research Association. Since this retrospective study does not fall under the scope of the Medical Research Involving Human Subjects Act (WMO), it was not subject to a prior review by a Medical Ethical Committee and written informed consent was not obtained. However, patient data were anonymized.

\section{Antibodies}

Mouse monoclonal antibodies HCA-2 (anti HLA-A, 1:1000) and HC-10 (anti HLA B/C, 1:500) were used to detect expression of the free heavy chain of the HLA class I molecule. Rabbit anti-human $\beta 2$-microglobulin (anti- $\beta 2 \mathrm{M}$; clone A-072, DAKO, 1:2000) and mouse antihuman HLA-E (clone MEM-E/02; Serotec, Germany [1:200]) antibodies were used in order to detect the light chain and non-classical HLA-E heavy chain respectively. Mouse monoclonal CD8 antibody (clone IA5, Leica Biosystems, Germany [1:500]) was used for the detection of the CD8+ T-cells.

\section{Immunochemistry}

Formalin-fixed, paraffin embedded tumor blocks were cut in $4 \mu \mathrm{m}$ sections using a microtome and deparaffinized in xylene. The endogenous peroxidase activity was blocked for 20 minutes using $0.3 \%$ hydrogen peroxide/methanol. The samples were subsequently rehydrated in $70 \%$ and $50 \%$ ethanol and antigen retrieval was performed by heating the samples to $97{ }^{\circ} \mathrm{C}$ for 10 minutes in citrate buffer (either $\mathrm{pH} 9.0$ or pH 6.0, DAKO, Glostrup, Denmark). Antibodies were diluted in phosphate buffered saline (PBS, Fresenius Kabi Bad Homburg, Germany) with $1 \%$ bovine serum albumin (BSA) and incubated overnight at room temperature. The slides were stained immunohistochemically with horseradish peroxidase (HRP)-conjugated anti-mouse IgG (DAKO envision) for 30 minutes at room temperature. NovaRed (Vector, Burlingame, USA) was applied as a chromagen followed by counterstaining with Mayer's hematoxylin (Klinipath). All washing steps were done with PBS. All slides were mounted with Pertex mounting medium (HistoLab, Sweden).

The microscopic evaluation and analysis of the HCA2, HC10, $\beta 2 \mathrm{M}$ and HLA-E staining was performed by two independent observers without prior knowledge 
of clinical or histopathological parameters (observer one $100 \%$ of the cohort, observer two $20 \%$ of the cohort). The inter-observer agreement was assessed by calculating Cohen's kappa coefficient resulting in a coefficient of $>0.70$ for all stainings which indicates a substantial interobserver agreement.

The grade of tumor differentiation was determined and classified as either poorly differentiated, moderately differentiated or well differentiated based on the immunohistochemically stained slides. Expression patterns of the previously mentioned antibodies were assessed according to the scoring system proposed by the Ruiter et al [46]. Using this method the entire slide is screened and the percentage of positive tumor cells was classified as: absent $0 \%$, sporadic 1-5\%, local 6-25\%, occasional $25-50 \%$, majority $51-75 \%$ and large majority $76-100 \%$ (1-6). Furthermore, this score includes intensity of the staining which is classified as negative, low, medium and high (0-3). The intensity was noted for all antibodies with the exception of CD8 since high intensity was always observed. The final score was based on both intensity and percentage and was categorized as 1-4 (low expression) and 5-9 (high expression).

\section{Quantification of infiltrating CD8+ T-cells}

CD8+ T-cell infiltration was assessed by screening five randomly captured high resolution (200X) images of each slide. The area of the tumor nests and stromal areas were marked and calculated using NIH-ImageJ software (v1.48). CD8 $+\mathrm{T}$ cells were counted by area and represented as the number of cells per mm2 of tumor area with a distinction between intraepithelial and stromal CD8+ T cells. The mean number of intraepithelial, stromal and total number of tumor-infiltrating CD8 $+\mathrm{T}$ cells were calculated and patients were dichotomized for high or low CD8 $+\mathrm{T}$ cell infiltration based on the mean CD8 $+\mathrm{T}$ cell infiltration for all patients.

\section{Statistical analysis}

Nonparametric Mann-Whitney $U$ test was used to compare continuous variables between patient groups and group comparisons of categorical data were performed by two-tailed $\chi 2$ test. Overall survival (OS) was defined as date of surgery until date of death due to any cause, or date of last follow-up with a maximum follow-up time of 5 years. When assessing survival based on HLA expression, low and high expression of HLA indicates the presence of a functional HLA molecule, i.e high expression of both $\beta 2 \mathrm{M}$ and the HLA heavy chain of HLA-A, HLA$\mathrm{B} / \mathrm{C}$ and HLA-E respectively. Survival was estimated by using Kaplan-Meier methodology and the log-rank test was used to compare the two curves. Univariate Cox proportional hazards model was used to study the effect of single determinants on OS. Multivariate Cox regression analysis was performed with variables that reached statistical significance in univariate analysis. Stepwise regression was employed to estimate the final model. Two-sided $\mathrm{P}$ values of $<0.05$ were considered statistically significant. Bonferroni correction was applied for multiple testing. Statistical software package SPSS 20.0 (SPSS, Chicago, IL) was used for data analysis. GraphPad Prism 6.02 (Graphpad Software, LA Jolla, CA) was used to estimate survival curves.

\section{ACKNOWLEDGMENTS}

We thank Dr. J. Neefjes (Netherlands Cancer Institute) and Dr. E.S. Jordanova (Free University Amsterdam) for providing antibodies against $\beta 2$-microglobulin, HCA2 and $\mathrm{HC} 10$.

\section{CONFLICTS OF INTEREST}

The authors declare no conflicts of interest.

\section{FINANCIAL SUPPORT}

This study was supported by a grant from the Netherlands Organisation for Health Research and Development (grant \# 40-00703-98-11626).

\section{Abbreviations}

B2M: $\beta 2$-microglobulin; BSA: Bovine Serum Albumin; HLA: Human Leucocyte Antigen; HRP: Horseradish Peroxidase; LICR: Ludwig Institute for Cancer Research; LUMC: Leiden University Medical Center; NK: Natural Killer; NSCLC: Non-Small Cell Lung Cancer; OS: Overall survival; PBS: Phosphate Buffered Saline; PD-1: programmed death 1; TIL: Tumorinfiltrating lymphocyte

\section{REFERENCES}

1. Herbst RS, Heymach JV, Lippman SM: Lung cancer. N Engl J Med 2008;359:1367-1380.

2. Siegel R, DeSantis C, Virgo K, Stein K, Mariotto A, Smith T, Cooper D, Gansler T, Lerro C, Fedewa S, Lin C, Leach C, Cannady RS, et al. Cancer treatment and survivorship statistics, 2012. CA Cancer J Clin 2012;62:220-241.

3. Torre LA, Bray F, Siegel RL, Ferlay J, Lortet-Tieulent J, Jemal A: Global cancer statistics, 2012. CA Cancer J Clin 2015;65:87-108.

4. van der Drift MA, Karim-Kos HE, Siesling S, Groen HJ, Wouters MW, Coebergh JW, de VE, Janssen-Heijnen ML: Progress in standard of care therapy and modest survival benefits in the treatment of non-small cell lung cancer patients in the Netherlands in the last 20 years. J Thorac Oncol 2012;7:291-298. 
5. Garon EB, Rizvi NA, Hui R, Leighl N, Balmanoukian AS, Eder JP, Patnaik A, Aggarwal C, Gubens M, Horn L, Carcereny E, Ahn MJ, Felip E, et al. Pembrolizumab for the treatment of non-small-cell lung cancer. N Engl J Med 2015;372:2018-2028.

6. Gettinger SN, Horn L, Gandhi L, Spigel DR, Antonia SJ, Rizvi NA, Powderly JD, Heist RS, Carvajal RD, Jackman DM, Sequist LV, Smith DC, Leming P, et al. Overall Survival and Long-Term Safety of Nivolumab (Anti-Programmed Death 1 Antibody, BMS-936558, ONO-4538) in Patients With Previously Treated Advanced Non-Small-Cell Lung Cancer. J Clin Oncol 2015;33:2004-2012.

7. Jia M, Feng W, Kang S, Zhang Y, Shen J, He J, Jiang L, Wang W, Guo Z, Peng G, Chen G, He J, Liang W: Evaluation of the efficacy and safety of anti-PD-1 and anti-PD-L1 antibody in the treatment of non-small cell lung cancer (NSCLC): a meta-analysis. J Thorac Dis 2015;7:455-461.

8. Nivolumab approved for lung cancer. Cancer Discov 2015;5:OF1.

9. Melief CJ, van der Burg SH: Immunotherapy of established (pre)malignant disease by synthetic long peptide vaccines. Nat Rev Cancer 2008;8:351-360.

10. Al-Shibli KI, Donnem T, Al-Saad S, Persson M, Bremnes RM, Busund LT: Prognostic effect of epithelial and stromal lymphocyte infiltration in non-small cell lung cancer. Clin Cancer Res 2008;14:5220-5227.

11. Bremnes RM, Al-Shibli K, Donnem T, Sirera R, Al-Saad S, Andersen S, Stenvold H, Camps C, Busund LT: The role of tumor-infiltrating immune cells and chronic inflammation at the tumor site on cancer development, progression, and prognosis: emphasis on non-small cell lung cancer. J Thorac Oncol 2011;6:824-833.

12. Djenidi F, Adam J, Goubar A, Durgeau A, Meurice G, de M, V, Validire P, Besse B, Mami-Chouaib F: CD8+CD103+ tumor-infiltrating lymphocytes are tumor-specific tissueresident memory $\mathrm{T}$ cells and a prognostic factor for survival in lung cancer patients. J Immunol 2015;194:3475-3486.

13. Donnem T, Hald SM, Paulsen EE, Richardsen E, Al-Saad S, Kilvaer TK, Brustugun OT, Helland A, Lund-Iversen M, Poehl M, Olsen KE, Ditzel HJ, Hansen O, et al. Stromal CD8+ T-cell Density-A Promising Supplement to TNM Staging in Non-Small Cell Lung Cancer. Clin Cancer Res. 2015;21:2635-2643.

14. Hiraoka K, Miyamoto M, Cho Y, Suzuoki M, Oshikiri T, Nakakubo Y, Itoh T, Ohbuchi T, Kondo S, Katoh H: Concurrent infiltration by CD8 $+\mathrm{T}$ cells and CD4 $+\mathrm{T}$ cells is a favourable prognostic factor in non-small-cell lung carcinoma. Br J Cancer 2006;94:275-280.

15. Schalper KA, Brown J, Carvajal-Hausdorf D, McLaughlin J, Velcheti V, Syrigos KN, Herbst RS, Rimm DL: Objective measurement and clinical significance of TILs in non-small cell lung cancer. J Natl Cancer Inst 2015;107.
16. Baba T, Shiota H, Kuroda K, Shigematsu Y, Ichiki Y, Uramoto H, Hanagiri T, Tanaka F: Clinical significance of human leukocyte antigen loss and melanoma-associated antigen 4 expression in smokers of non-small cell lung cancer patients. Int J Clin Oncol 2013;18:997-1004.

17. Hanagiri T, Shigematsu Y, Shinohara S, Takenaka M, Oka S, Chikaishi Y, Nagata Y, Baba T, Uramoto H, So T, Yamada S: Clinical significance of expression of cancer/testis antigen and down-regulation of HLA class-I in patients with stage I non-small cell lung cancer. Anticancer Res 2013;33:2123-2128.

18. Hanagiri T, Shigematsu Y, Kuroda K, Baba T, Shiota H, Ichiki Y, Nagata Y, Yasuda M, Uramoto H, So T, Takenoyama M, Tanaka F: Prognostic implications of human leukocyte antigen class I expression in patients who underwent surgical resection for non-small-cell lung cancer. J Surg Res 2013;181:e57-e63.

19. Kikuchi E, Yamazaki K, Torigoe T, Cho Y, Miyamoto M, Oizumi S, Hommura F, Dosaka-Akita H, Nishimura M: HLA class I antigen expression is associated with a favorable prognosis in early stage non-small cell lung cancer. Cancer Sci 2007;98:1424-1430.

20. Yie SM, Yang H, Ye SR, Li K, Dong DD, Lin XM: Expression of human leucocyte antigen G (HLA-G) is associated with prognosis in non-small cell lung cancer. Lung Cancer 2007;58:267-274.

21. Carosella ED, HoWangYin KY, Favier B, LeMaoult J: HLA-G-dependent suppressor cells: Diverse by nature, function, and significance. Hum Immunol 2008;69:700-707.

22. Lepin EJ, Bastin JM, Allan DS, Roncador G, Braud VM, Mason DY, van der Merwe PA, McMichael AJ, Bell JI, Powis SH, O'Callaghan CA: Functional characterization of HLA-F and binding of HLA-F tetramers to ILT2 and ILT4 receptors. Eur J Immunol 2000;30:3552-3561.

23. Lin A, Zhang X, Ruan YY, Wang Q, Zhou WJ, Yan WH: HLA-F expression is a prognostic factor in patients with non-small-cell lung cancer. Lung Cancer 2011;74:504-509.

24. Kochan G, Escors D, Breckpot K, Guerrero-Setas D: Role of non-classical MHC class I molecules in cancer immunosuppression. Oncoimmunology 2013;2:e26491.

25. van Hall T., Oliveira CC, Joosten SA, Ottenhoff TH: The other Janus face of Qa-1 and HLA-E: diverse peptide repertoires in times of stress. Microbes Infect 2010;12:910-918.

26. van Esch EM, Tummers B, Baartmans V, Osse EM, Ter HN, Trietsch MD, Hellebrekers BW, Holleboom CA, Nagel HT, Tan LT, Fleuren GJ, van Poelgeest MI, van der Burg SH, Jordanova ES: Alterations in classical and nonclassical HLA expression in recurrent and progressive HPV-induced usual vulvar intraepithelial neoplasia and implications for immunotherapy. Int J Cancer 2014;135:830-842.

27. Gooden M, Lampen M, Jordanova ES, Leffers N, Trimbos JB, van der Burg SH, Nijman H, van HT: HLA-E expression by gynecological cancers restrains tumor-infiltrating 
CD8(+) T lymphocytes. Proc Natl Acad Sci U S A 2011;108:10656-10661.

28. Alberg AJ, Brock MV, Samet JM: Epidemiology of lung cancer: looking to the future. J Clin Oncol 2005;23:3175-3185.

29. Korkolopoulou P, Kaklamanis L, Pezzella F, Harris AL, Gatter KC: Loss of antigen-presenting molecules (MHC class I and TAP-1) in lung cancer. Br J Cancer 1996;73:148-153.

30. Sakurai H, Asamura H, Goya T, Eguchi K, Nakanishi Y, Sawabata N, Okumura M, Miyaoka E, Fujii Y: Survival differences by gender for resected non-small cell lung cancer: a retrospective analysis of 12,509 cases in a Japanese Lung Cancer Registry study. J Thorac Oncol 2010;5:1594-1601.

31. Rizvi NA, Hellmann MD, Snyder A, Kvistborg P, Makarov V, Havel JJ, Lee W, Yuan J, Wong P, Ho TS, Miller ML, Rekhtman N, Moreira AL, et al. Cancer immunology. Mutational landscape determines sensitivity to PD-1 blockade in non-small cell lung cancer. Science 2015;348:124-128.

32. Kikuchi E, Yamazaki K, Nakayama E, Sato S, Uenaka A, Yamada N, Oizumi S, Dosaka-Akita H, Nishimura M: Prolonged survival of patients with lung adenocarcinoma expressing XAGE-1b and HLA class I antigens. Cancer Immun 2008;8:13.

33. Ramnath N, Tan D, Li Q, Hylander BL, Bogner P, Ryes L, Ferrone S: Is downregulation of MHC class I antigen expression in human non-small cell lung cancer associated with prolonged survival? Cancer Immunol Immunother 2006;55:891-899.

34. Pan ZK, Ye F, Wu X, An HX, Wu JX: Clinicopathological and prognostic significance of programmed cell death ligand1 (PD-L1) expression in patients with non-small cell lung cancer: a meta-analysis. J Thorac Dis 2015;7:462-470.

35. Ulbrecht M, Couturier A, Martinozzi S, Pla M, Srivastava R, Peterson PA, Weiss EH: Cell surface expression of HLA-E: interaction with human beta2-microglobulin and allelic differences. Eur J Immunol 1999;29:537-547.

36. Guma M, Busch LK, Salazar-Fontana LI, Bellosillo B, Morte C, Garcia P, Lopez-Botet M: The CD94/NKG2C killer lectin-like receptor constitutes an alternative activation pathway for a subset of CD8+ T cells. Eur J Immunol 2005;35:2071-2080.

37. de Kruijf EM, Sajet A, van Nes JG, Natanov R, Putter H, Smit VT, Liefers GJ, van den Elsen PJ, van de Velde CJ, Kuppen PJ: HLA-E and HLA-G expression in classical HLA class I-negative tumors is of prognostic value for clinical outcome of early breast cancer patients. J Immunol 2010;185:7452-7459.
38. Spaans VM, Peters AA, Fleuren GJ, Jordanova ES: HLA-E expression in cervical adenocarcinomas: association with improved long-term survival. J Transl Med 2012;10:184.

39. Bossard C, Bezieau S, Matysiak-Budnik T, Volteau C, Laboisse CL, Jotereau F, Mosnier JF: HLA-E/beta2 microglobulin overexpression in colorectal cancer is associated with recruitment of inhibitory immune cells and tumor progression. Int J Cancer 2012;131:855-863.

40. Ishigami S, Arigami T, Okumura H, Uchikado Y, Kita Y, Kurahara H, Maemura K, Kijima Y, Ishihara Y, Sasaki K, Uenosono Y, Natsugoe S: Human Leukocyte Antigen (HLA)-E and HLA-F Expression in Gastric Cancer. Anticancer Res 2015;35:2279-2285.

41. Zhen ZJ, Ling JY, Cai Y, Luo WB, He YJ: Impact of HLA-E gene polymorphism on HLA-E expression in tumor cells and prognosis in patients with stage III colorectal cancer. Med Oncol 2013;30:482.

42. Johnson DB, Rioth MJ, Horn L: Immune checkpoint inhibitors in NSCLC. Curr Treat Options Oncol 2014; 15:658-669.

43. Levy EM, Sycz G, Arriaga JM, Barrio MM, Von Euw EM, Morales SB, Gonzalez M, Mordoh J, Bianchini M: Cetuximab-mediated cellular cytotoxicity is inhibited by HLA-E membrane expression in colon cancer cells. Innate Immun 2009;15:91-100.

44. Derre L, Corvaisier M, Charreau B, Moreau A, Godefroy E, Moreau-Aubry A, Jotereau F, Gervois N: Expression and release of HLA-E by melanoma cells and melanocytes: potential impact on the response of cytotoxic effector cells. J Immunol 2006;177:3100-3107.

45. Tanoue LT, Detterbeck FC: New TNM classification for non-small-cell lung cancer. Expert Rev Anticancer Ther 2009;9:413-423.

46. Ruiter DJ, Ferrier CM, van Muijen GN, Henzen-Logmans SC, Kennedy S, Kramer MD, Nielsen BS, Schmitt M: Quality control of immunohistochemical evaluation of tumour-associated plasminogen activators and related components. European BIOMED-1 Concerted Action on Clinical Relevance of Proteases in Tumour Invasion and Metastasis. Eur J Cancer 1998;34:1334-1340. 